\title{
Sorting Analysis of Household Food Waste-Development of a Methodology Compatible with the Aims of SDG12.3
}

\author{
Tomoko Okayama $^{1}$, Kohei Watanabe ${ }^{2, *}$ and Hajime Yamakawa ${ }^{3}$ \\ 1 Faculty of Regional Development, Taisho University, Tokyo 170-8470, Japan; t_okayama@mail.tais.ac.jp \\ 2 Department of Sociology, Faculty of Liberal Arts, Teikyo University, Tokyo 192-0395, Japan \\ 3 Faculty of Life and Environmental Sciences, Kyoto Prefectural University, Kyoto 606-8522, Japan; \\ yamakawa@kpu.ac.jp \\ * Correspondence: kw10004@cantab.net
}

Citation: Okayama, T.; Watanabe, K.; Yamakawa, H. Sorting Analysis of Household Food WasteDevelopment of a Methodology Compatible with the Aims of SDG12.3. Sustainability 2021, 13, 8576. https://doi.org/10.3390/su13158576

Academic Editor: Ada Margarida

Correia Nunes Da Rocha

Received: 12 June 2021

Accepted: 24 July 2021

Published: 31 July 2021

Publisher's Note: MDPI stays neutral with regard to jurisdictional claims in published maps and institutional affiliations.

Copyright: (c) 2021 by the authors. Licensee MDPI, Basel, Switzerland. This article is an open access article distributed under the terms and conditions of the Creative Commons Attribution (CC BY) license (https:// creativecommons.org/licenses/by/ $4.0 /)$.

\begin{abstract}
Target 12.3 of the United Nations Sustainable Development Goals (SDGs) calls for halving per capita global food waste at the retail and consumer levels, by 2030. The Food Waste Index is suggested as a methodology for grasping the situation. This paper focuses on the consumer level (household food waste). We argue that in order for generating useful information for devising and implementing effective measures for reducing food waste, it should be measured at Level 3 of the Food Waste Index, based on sorting analysis of generated waste, and making a distinction between avoidable and non-avoidable food waste. Furthermore, a breakdown by subcategories that reflect the flow of food in the household could help identify target behaviours. We have developed a categorisation scheme that is internationally agreeable and adoptable, and (1) generates useful information for policy-making and for tackling with reduction of food waste, (2) makes clear the concept of avoidable food waste, and (3) is practical and does not overcomplicate the work of grasping the situation of food wastage. Results of workshops regarding this scheme suggest that the scheme satisfies the criteria. This scheme has been applied to a few sorting analyses of household food waste in Japan, and their results are compared.
\end{abstract}

Keywords: food waste index; household food waste; waste characterisation; waste sorting analysis; avoidable food waste; preparation residues; SDG target 12.3; methodology development; assessment of current situation

\section{Introduction}

FAO has indicated that about one third of the food produced globally is lost every year [1]. This leads to substantial impacts on climate, land, and water [2]. Under these circumstances, Target 12.3 of the United Nations Sustainable Development Goals (SDGs) was set to "by 2030, halve per capita global food waste at the retail and consumer levels and reduce food losses along production and supply chains, including post-harvest losses".

As indicators of food waste for target 12.3, the Food Waste Index was developed by UNEP [3]. It has three levels of accuracy and detail of data, and Level 2 is the recommended approach [3] (p. 10). At Level 2, the requirement is to measure food waste using suitable methods for each sector (all or part of retail, food service and household) [3] (p. 76).

However, the Level 2 index provides only figures about the total amount of food waste and does not distinguish between avoidable and non-avoidable parts discharged from each sector. Such index could be used for grasping and tracking status, but could not be used for designing and evaluating policies for preventing food waste. In order to design policies to realise food waste prevention, we need more detailed information that can specify necessary behaviours to promote.

One of the suitable methods for obtaining such information is waste sorting analysis [3] (p. 78). However, if we require classifying food waste into many complicated categories, the cost and effort to gather information will increase; if the concept of each category and 
its classification method are ambiguous and difficult to understand, the sorting procedure will take too much time and will cause many errors. Moreover, users of these results may misinterpret them. Therefore, it is necessary to make the concept of categorisation clear and easy to understand and to balance the requirement for detailed information with its cost. Such consideration is also necessary for the international acceptability of the methodology.

Three criteria are therefore expected to be met for developing classification systems suitable for informing policies to prevent food waste:

(1) It should be useful for proposing target behaviours/policies for prevention;

(2) It should make the concepts of categorisation clear and easy to understand;

(3) It should be practical and should not over-complicate the work of analysing the situation of food wastage.

The aim of this paper is to (1) discuss what definition and classification system of household avoidable food waste is useful for providing information to prevent household food waste, (2) propose an internationally agreeable method for the sorting analysis of household food waste, based on the above discussion, and (3) verify that the method meets the above criteria. The reason for focusing on household food waste is that there are many issues with existing measurement of household food waste, and it has a major share among the sectors that should be included in the Food Waste Index [3] (p. 55).

The major novelties and contributions of this paper are that we suggest (1) the avoidability of food waste should be judged by whether the item is intentionally removed or not, (2) it is most useful to categorise avoidable food waste from the flow of food (stages) in the household, i.e., whether they are food ingredients, ready-to-be-eaten food, or leftovers after a meal, and (3) presenting results of sorting analysis, applying the above method, in some municipalities in Japan.

\section{Previous Research and Issues on the Classification System}

\subsection{Avoidability and Edibility}

In order to clarify the information required for making food waste-prevention policies, avoidability should be discussed first. Edibility is related to avoidability because the edible part of food can be prevented from being wasted by human ingestion ("eating it up"). The Food Waste Index introduces classification by edibility in Level 3. FUSIONS reviewed the terminology related to household food waste in available literature, and reported that "avoidable" is used for items that are "edible or possibly edible foods, regardless of whether they are edible at point of disposal, unplanned waste e.g., leftovers, preference losses" [4] (p. 100). However, there are some issues with classifying food waste by its edibility.

One of the issues is its situation-dependency. UNEP, in explaining the definition of inedible, states that "what is considered inedible varies among users (e.g., chicken feet are consumed in some food supply chains but not others), changes over time, and is influenced by a range of variables including culture, socio-economic factors, availability, price, technological advances, international trade and geography" [3] (p. 19).

In some literature, authors judged the edibility of a food item according to typical food consumption habits in the countries being studied [5,6]. However, it still leaves ambiguity on the judgement of typical food consumption habits, and the judgement of some items on the borderline.

The Waste and Resources Action Programme (WRAP) in the U.K. sets a separate category of "possibly avoidable" for "food and drink that some people eat and others do not, e.g., bread crusts and potato skins" [7] (p. 5). Other categories of food waste are "avoidable" and "unavoidable". This type of categorisation could be a solution, but the boundary is still left ambiguous. WRAP later changed the classification axis from avoidability to edibility [8]. For this change, they conducted a questionnaire survey to understand to what extent people in the U.K. actually eat some of the "possibly avoidable" and "unavoidable" items, or they perceive them as edible. WRAP reclassified all items of "possibly avoidable" and "unavoidable" into "edible" or "inedible" by using its results. This method is valid for categorising food waste items into "edible" and "inedible". 
However, the WRAP survey also showed that the perception of edibility and eating habits of "possibly avoidable" depended on the person, and the responses were varied [8]. From the viewpoint of avoidability, this raises a question of whether it is meaningful to divide items such as preparation residues into edible and inedible. A method to reduce preparation residues would probably involve some improved or novel cooking manner, regardless whether the residue is considered edible or inedible. This is rather different from measures for preventing edible parts being wasted. Considering the usefulness of the data and the cost for measurement (identification), we concluded that in many cases it is not cost effective to assess the edibility of preparation residues. At a basic level of classification, preparation residues should be treated as one category without dividing them into edible or inedible parts. Parts of preparation residues should not be combined with other edible parts, even if they are judged as edible.

Another issue is how to classify unused food that contains both edible and inedible parts, such as an apple, which has edible flesh and an inedible core. Food Loss and Waste Protocol [9] require separating even a whole apple into edible and inedible parts. The protocol recommends using conversion factors, if it is difficult to separate them physically, yet that is still time-consuming. This also diverges from the viewpoint of avoidability. If an apple that would have been thrown away had never been purchased, not only the flesh but also the core of the apple can be avoided from being disposed of; so, the whole apple could be treated as avoidable in this case.

This issue is also related to the concept of "excessive removal" in Japan, which is defined as the disposal of edible parts of food that were removed while trying to remove the inedible parts during preparation at home, such as a thickly peeled skin of radish [10]. This means that preparation residues should be divided into edible parts, as excessive removal, and "purely" inedible parts. The Japanese Ministry of Agriculture, Forestry and Fisheries originally estimated the amount of excessive removal as the gap between the weight of actual residues from the food waste survey and the expected residues, according to the conversion factors in the Standard Tables of Food Composition in Japan [11]. This estimation is possible when using data from food waste diary surveys. It is, however, impossible to calculate it in the above manner when using data from sorting analyses, since researchers cannot obtain the data on the original amount of food corresponding to the preparation residues. Considering the balance between the effectiveness for prevention and the cost for obtaining the data, it is probably reasonable to disregard "excessive removal".

\subsection{Subcategories for Prevention}

Several classification systems of edible/avoidable household food waste have been proposed. In Japan, Kyoto City and Kyoto University proposed a classification system of food waste based on its cause ("untouched food" and "leftovers") and have been conducting sorting analysis of household food waste for many years, since the 1980s [12,13]. The Japanese Ministry of Environment followed a similar classification system and adopted three major categories of edible household food waste [10]. Categories based on its causes can be easily connected to the corresponding behaviours for its prevention. For example, untouched/unused food can be reduced by not buying too much and managing the refrigerator properly, while leftovers can be reduced by not cooking too much and eating all the food that has been prepared. Several recent studies in other countries also adopted a similar classification system (Table 1). Although they used different names for the basis of their systems, such as life cycle stage [5] or consumption status [6], identical categories of food waste can be observed: leftovers, whole unused food, partly consumed food, etc.

WRAP, on the other hand, have adopted food type as the basis of its classification, and it classified food waste into 15 groups and subdivided them into 150 food types in 2012 [7] (p. 69). In this study, component parts of meals were recorded to specific food categories where possible e.g., a dish consisting of meat and two vegetables was recorded as "chicken, potatoes and carrots", and other composite meals, such as soups, sandwiches, and savoury products, are classified as "home made and pre-prepared meals" [14]. 
Table 1. Comparison of the definition/explanation of subcategories based on its causes.

\begin{tabular}{|c|c|c|c|c|c|c|}
\hline \multirow{2}{*}{ This Study } & \multicolumn{2}{|c|}{ Unused Food } & \multirow{2}{*}{ Leftovers } & \multirow{2}{*}{ Unclassifiable } & \multicolumn{2}{|c|}{ Intentionally Removed Parts } \\
\hline & Whole unused & Partly unused & & & Possibly avoidable & Inedible \\
\hline \multirow[b]{2}{*}{$\begin{array}{l}\text { MOE Japan } \\
(2019)[10]\end{array}$} & \multicolumn{2}{|c|}{ Untouched/unused food } & Leftovers & - & Excessive removal & Inedible \\
\hline & \multicolumn{2}{|c|}{$\begin{array}{l}\text { Food that was not used as a } \\
\text { cooking ingredient or was not } \\
\text { used or served as a } \\
\text { ready-to-be-eaten food, and was } \\
\text { discarded due to expiration etc. }\end{array}$} & $\begin{array}{l}\text { Food that was } \\
\text { served cooked or } \\
\text { raw on the table, } \\
\text { but was not whole } \\
\text { consumed and was } \\
\text { discarded. }\end{array}$ & $\begin{array}{l}\text { No such } \\
\text { category }\end{array}$ & $\begin{array}{l}\text { Edible parts of food } \\
\text { that were } \\
\text { excessively } \\
\text { removed when } \\
\text { people removed the } \\
\text { inedible parts for } \\
\text { preparation, such } \\
\text { as thickly peeled } \\
\text { skin of vegetable. }\end{array}$ & $\begin{array}{l}\text { Parts of food } \\
\text { that needs to } \\
\text { be removed, } \\
\text { mainly } \\
\text { during the } \\
\text { cooking } \\
\text { process, such } \\
\text { as the skin of } \\
\text { vegetables } \\
\text { and fruits, } \\
\text { bones of } \\
\text { meat and } \\
\text { fish. }\end{array}$ \\
\hline \multirow[b]{2}{*}{$\begin{array}{c}\text { Lebersorger } \\
\text { \& Schneider } \\
\text { (2011) [5] }\end{array}$} & $\begin{array}{l}\text { Whole unused } \\
\text { food }\end{array}$ & $\begin{array}{c}\text { Part consumed } \\
\text { food }\end{array}$ & Leftovers & $\begin{array}{c}\text { Not } \\
\text { classifiable } \\
\text { remainder }\end{array}$ & \multicolumn{2}{|c|}{$\begin{array}{c}\text { Non avoidable/Preparation } \\
\text { residues }\end{array}$} \\
\hline & $\begin{array}{c}\text { Food in its } \\
\text { originally } \\
\text { sealed } \\
\text { unopened } \\
\text { sales } \\
\text { packaging, } \\
\text { individually } \\
\text { wrapped food } \\
\text { items which } \\
\text { are part of a } \\
\text { larger sales } \\
\text { packaging, or } \\
\text { whole item of } \\
\text { food which is } \\
\text { unpacked or } \\
\text { available by } \\
\text { piece. }\end{array}$ & $\begin{array}{l}\text { Whole single } \\
\text { items of a food } \\
\text { which is usually } \\
\text { sold bunched, } \\
\text { cut food, or } \\
\text { part consumed } \\
\text { food in its } \\
\text { original sales- } \\
\text { packaging or in } \\
\text { other } \\
\text { packaging. }\end{array}$ & $\begin{array}{c}\text { Foods } \\
\text { post-preparation } \\
\text { /consumption and } \\
\text { comprise food } \\
\text { which has been } \\
\text { bitten into, } \\
\text { prepared food or } \\
\text { food consisting of } \\
\text { different } \\
\text { components which } \\
\text { has been served } \\
\text { before, as well as } \\
\text { convenience food } \\
\text { which has already } \\
\text { been prepared for } \\
\text { instantaneous } \\
\text { consumption by } \\
\text { cooking, warming } \\
\text { or baking. Some of } \\
\text { leftovers such as } \\
\text { used chewing gum } \\
\text { are non-avoidable. }\end{array}$ & $\begin{array}{l}\text { All food items } \\
\text { which could } \\
\text { not be } \\
\text { classified into } \\
\text { any of the } \\
\text { subcategories } \\
\text { of avoidable } \\
\text { food waste, } \\
\text { which } \\
\text { comprised } \\
\text { tiny, not } \\
\text { identifiable } \\
\text { pieces. This } \\
\text { may also } \\
\text { include some } \\
\text { percentages } \\
\text { of non- } \\
\text { avoidable } \\
\text { food waste. }\end{array}$ & \multicolumn{2}{|c|}{$\begin{array}{l}\text { Biowastes that are generated in the } \\
\text { course of food preparation. They } \\
\text { comprise parts of food which are } \\
\text { inedible or which usually are not } \\
\text { consumed, such as outside leaves of } \\
\text { lettuce, peelings, apple cores, bones, } \\
\text { eggshells, coffee grounds including } \\
\text { coffee filters or tea bags. }\end{array}$} \\
\hline & $\begin{array}{l}\text { Unconsumed } \\
\text { food }\end{array}$ & $\begin{array}{c}\text { Partly } \\
\text { consumed food }\end{array}$ & Food leftovers & $\begin{array}{l}\text { Unidentified } \\
\text { food items }\end{array}$ & \multicolumn{2}{|c|}{ Unavoidable food waste } \\
\hline $\begin{array}{l}\text { Elmelech et. } \\
\text { al. (2018) [6] }\end{array}$ & $\begin{array}{l}\text { Food in its } \\
\text { original state } \\
\text { (with or } \\
\text { without a } \\
\text { package) (e.g., } \\
\text { uneaten } \\
\text { tomato, } \\
\text { uncooked egg, } \\
\text { sealed yogurt } \\
\text { cup) }\end{array}$ & $\begin{array}{l}\text { Food product } \\
\text { that was found } \\
\text { in its original } \\
\text { unsealed } \\
\text { package or was } \\
\text { partly eaten } \\
\text { (e.g., bitten } \\
\text { tomato, } \\
\text { half-full } \\
\text { package of } \\
\text { cheese) }\end{array}$ & $\begin{array}{c}\text { Formed after the } \\
\text { preparation process } \\
\text { and during food } \\
\text { consumption (e.g., } \\
\text { salad, cooked rice, } \\
\text { pizza) }\end{array}$ & $\begin{array}{l}\text { Avoidable } \\
\text { food items } \\
\text { that were not } \\
\text { identifiable, } \\
\text { due to their } \\
\text { physical state } \\
\text { or size (e.g., } \\
\text { very small } \\
\text { food items) }\end{array}$ & \multicolumn{2}{|c|}{$\begin{array}{l}\text { Waste arising from food preparation } \\
\text { (e.g., edges of cucumbers cut for a } \\
\text { salad) or not regarded as fit for } \\
\text { human consumption (i.e., potato } \\
\text { peels) }\end{array}$} \\
\hline
\end{tabular}

WRAP had also introduced an earlier classification, based on the preparation state of food, such as "fresh, raw or minimally processed", "cooked/prepared at home", "ready to consume when purchased", "cooked", "pre-prepared and cooked at home", etc., [15]. This 
classification is deemed a combination of the state of the food at the time of sale and the state of cooking at the time of disposal.

Several classification systems are possible for subcategories; but what kind of classification system is suitable for informing policies to prevent household food waste (i.e., criterion (1) suggested in Section 1? Classification by cause makes it easy to understand the relationship between food waste items and behaviours for prevention, and therefore is expected to have high sensibility as an indicator of policy effectiveness. Classification by the state of food preparation has similar characteristics. However, it is difficult to determine detailed classifications of cooked or prepared food by its state, as many items are prepared at home. Therefore, when criteria (2), ease of understanding the categories, and (3), the practicality of classification work, are taken into account, classification by cause is considered to better fulfil all three criteria.

Classification by food type is useful to reveal target food items that have a large share in food waste, but it is difficult to classify the diverse mix of food items that are disposed of as leftovers. It is considered more effective to classify avoidable food waste into two or three categories by cause first, and then into further subcategories by food type, if it is feasible, considering criteria (3).

By setting up hierarchical levels in the classification system, it becomes possible to choose the level of their detail according to objectives and constraints, such as cost. This is also useful in making survey data, from different locations and conducted by different entities, comparable.

\subsection{Packaging Attached to Unused Food}

Another issue is whether containers and packaging containing food waste should be removed or not when measuring food waste. The Food Loss \& Waste Protocol requires that the weight of containers and packaging should be excluded when reporting the weight of food waste, and provides a method for that purpose [9]. However, as the Food Loss \& Waste Protocol also acknowledges, this is extremely time-consuming with respect to sorting analysis.

Based on a case study that was conducted in Austria, Lebersorger \& Schneider argued that the share of containers and packaging is small compared to the food waste contained in them, and there is no need to remove them in sorting analyses aimed at food waste [5]. According to the case of a study that took place in the city of Matsumoto, Japan, for which the authors conducted an interview and a literature survey, a comparison of the composition with and without the packaging showed that even the largest difference between them was less than $1 \%$. Therefore, if the influence of the packaging is presumed to be small and there are constraints such as cost, weighing without removing the packaging should be allowed.

\section{Materials and Methods}

\subsection{Definitions and the Concept of Major Categories of Avoidable Food Waste}

We define avoidable food waste as consisting of "unused foods" and "leftovers" among total household food waste, based on the above discussion. In our definition, avoidable food waste does not contain preparation residues, even if they may be potentially edible. Unused foods are further divided into two categories: A: unused ingredients (food material for cooking) and B: unused ready-to-be-eaten foods (yet to be put on the table, or one whole unit of food item prepared to its last step before consumption). Hence, avoidable food waste consists of categories A, B and a third category C: leftovers (including leftover drinks).

Aside from these, we will classify the remainder of food waste as D: intentionally removed parts (food parts that are generally not eaten) as not constitutive of avoidable food waste. This includes preparation residues, which are parts of food materials intentionally removed in the process of cooking, as well as parts that remain on the plate after meals, such as fruit seeds, clamshells, and bare corncob. 
Table 2 shows the definitions of these categories. The items situated between the two thickest lines in Table 2 are the classifications of avoidable food waste that our research group has established. Figure 1 shows how avoidable and non-avoidable food waste are generated during the flow of processes from the input of foods into the household (buying etc.) to eating and disposal.

Table 2. Definition of major categories.

\begin{tabular}{|c|c|c|}
\hline \multicolumn{2}{|c|}{ Major Categories } & Definition of Major Categories \\
\hline \multirow[b]{2}{*}{$\begin{array}{c}\text { A/B } \\
\text { Unused food }\end{array}$} & $\begin{array}{c}\mathrm{A} \\
\text { Unused ingredients }\end{array}$ & $\begin{array}{l}\text { Unused ingredients (unused entirely or in portion) } \\
\text { (fresh food and processed food but not ready-to-be-eaten food }{ }^{*} 1 \text {. }\end{array}$ \\
\hline & $\begin{array}{c}\text { B } \\
\text { Unused ready-to-be-eaten food }\end{array}$ & $\begin{array}{l}\text { Ready-to-be-eaten food }{ }^{*} 1 \text { that are yet to be put on the plate (table), or } \\
\text { one whole unit of food with no traces of eating. Ready-to-be-eaten } \\
\text { food other than leftovers. } \\
\text { In principle, ready-to-be-eaten food found with packaging is } \\
\text { classified in this category, but there are some exceptions }{ }^{*} 2 \text {. }\end{array}$ \\
\hline \multicolumn{2}{|c|}{ C Leftovers } & $\begin{array}{l}\text { Ready-to-be-eaten food that can be assumed to have been served on } \\
\text { the table and partially eaten and then thrown away }{ }^{*} \text {. } \\
\text { The food in this category is in principle not in packaging, but there } \\
\text { are some exceptions. See } * 2 \text {. }\end{array}$ \\
\hline \multicolumn{2}{|c|}{$\begin{array}{l}\text { D Intentionally } \\
\text { removed parts }\end{array}$} & $\begin{array}{c}\text { Intentionally removed and discarded parts of food commonly not } \\
\text { eaten. However, food that is no longer edible due to cooking errors or } \\
\text { spoilage is excluded. }\end{array}$ \\
\hline
\end{tabular}

*1: Ready-to-be-eaten food is food that has been prepared up to the last step before it is eaten or is ready to eat (e.g., ready meals, retort food, cup noodles, confectionery, pastries, etc.). *2: Exceptions are such food in packaging that can function as dishware (food expected to be eaten directly from packaging), which are normally expected to be consumed in one sitting (e.g., packed lunches, portion-sized tubs of yoghurt), but which have been disposed of after only being partially eaten.

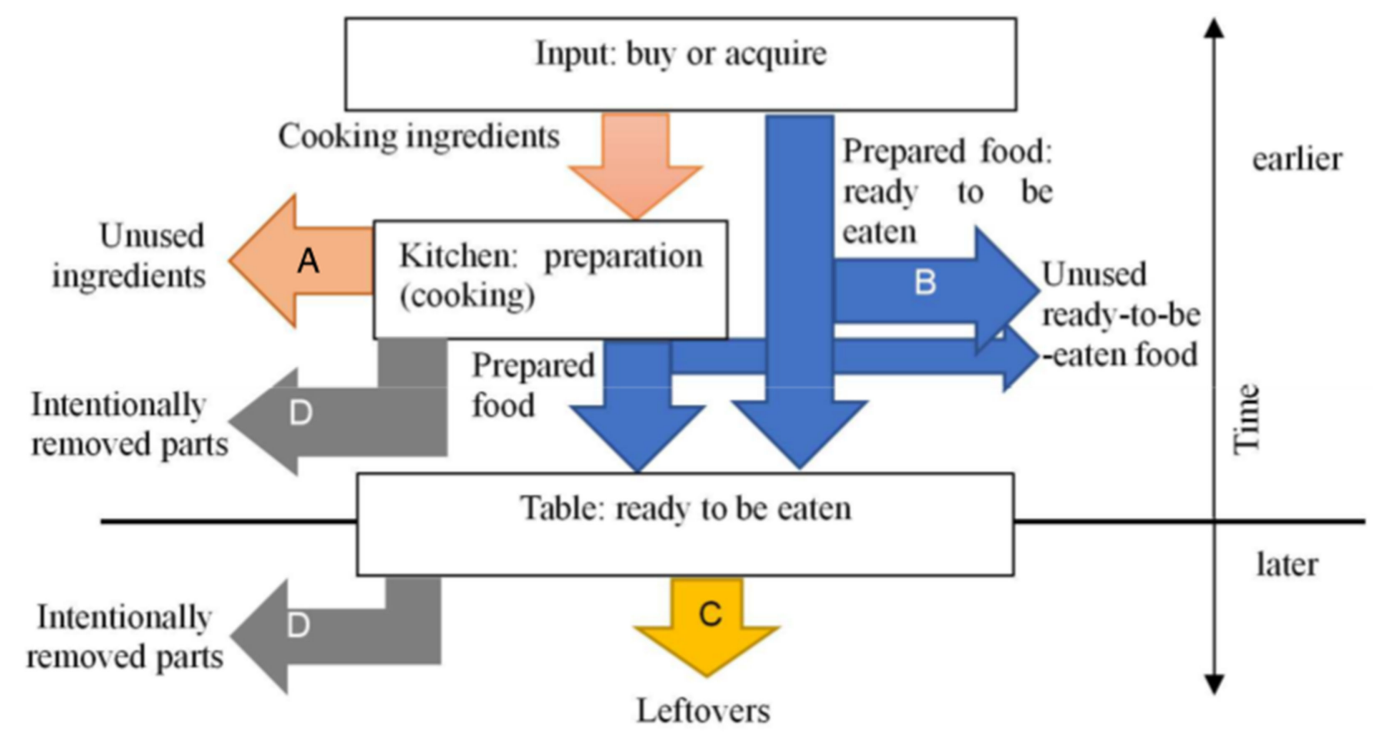

Figure 1. Generation of waste in the flow of food in households.

\subsubsection{Category A: Unused Ingredients}

Cooking ingredients are foods that are generally expected to take part in some form of cooking or preparation before being laid on the table for consumption. They include fresh foods, such as vegetables, fruits, fresh seafood, and dressed meat; processed foods, such as dairy products (including milk), tofu, natto (fermented soybeans), bread (excluding pastry buns and other bakery products fully prepared for consumption), and ham or bacon, and other perishable processed products that are typically delivered to stores daily. Seasonings; some kinds of frozen foods, such as mixed vegetables; canned sweet corn; jams and various sauces in package and such products are also considered ingredients. Cooking ingredients are usually sold in designated sections of supermarkets. Put simply, ingredients are foods 
typically bought at supermarkets in preparation for cooking. We classify food ingredients unused and disposed as category $\mathbf{A}$.

\subsubsection{Category B: Unused Ready-to-Be-Eaten Foods}

Ready-to-be-eaten foods are foods prepared until the last step before consumption or are purchased ready to eat, and they include: sandwiches, jiao-zi dumplings, steamed meat buns, fried foods, salads sold as ready-to-be-eaten at deli or bakery sections of a supermarket, canned foods (such as canned cooked sardines), foods contained in jars (such as pickles), ready-to-eat dishes packed in retort pouches (such as curry), "dry foods" prepared up to the last step before consumption (such as instant cup noodles, sweets and snacks, including traditional Japanese sweets as well as western sweets).

We classify uneaten ready-to-be-eaten foods, disposed of without being eaten, as $\mathbf{B}$. Those that are partly eaten and disposed of are classified as $\mathbf{C}$.

\subsubsection{Category C: Leftovers}

Ready-to-be-eaten foods or prepared dishes (for example, put on a plate and laid on the table) that appear to have been disposed after being partially eaten count as leftovers. In principle, items classified as $\mathbf{C}$ are found without packaging. However, partially eaten food, left in packaging, that is designed to serve as a plate/bowl (food that is designed to be eaten directly from the packaging) also qualifies as C: leftovers. Parts that may have been left on the plate but are not expected to be eaten, such as bones are not $\mathbf{C}$ (they are $\mathbf{D}$ : non-avoidable).

\subsection{Detailed Categories of the Classification and the Levels Scheme}

The detailed classifications of food waste are shown in Table 3, which is in accordance with the conceptual diagram shown in Figure 1. Table 3 shows the subcategories that break down the above categories further. The table also indicates the five levels of the classification system based on the level of its detail.

\subsubsection{Subcategories of Avoidable Food Waste (Categories A, B, and C) in the Proposed Classification}

We classify unused foods A/B into A: unused ingredients (entirely or partly unused) and $\mathbf{B}$ : unused or uneaten ready-to-be-eaten foods. Both $\mathbf{A}$ and $\mathbf{B}$ can be further divided into subcategories 1 or 2 . Subcategory 1 refers to packaged foods, unopened and discarded, while 2 refers to foods that were never packaged or, at some point, were put in packaging but have been opened.

Hence, $\mathbf{A} 1$ refers to packaged ingredients that have not been opened (note that it does not need to be sealed). A2 refers to ingredients not in packaging or in opened packaging, and can be further classified into $\mathbf{A 2 w}$ : whole ingredients (i.e., uncut, etc.) and $\mathbf{A} 2 \mathbf{p}$ : partly used ingredients. Examples of A1 would be discarded, whole, packaged food ingredients, such as a whole, packaged cucumber, or a whole packaged quarter of a cabbage head (In Japanese supermarkets, it is common to sell such big vegetables cut in half or quarters and wrapped in plastic film). Also, a remaining whole cucumber, in an opened package that had contained a number of cucumbers, is classified as A2w. However a remainder of a cucumber, partially cut off and used, regardless of the size of the portion remaining (as long as the portion can be used for preparation), is classified as A2p. We would classify an opened package containing a quarter of a cabbage head as A2p as well. Among A2w, fruits and vegetables appearing not to have been sold and purchased, but obtained from places such as household vegetable gardens, are classified as A2wf.

B1 consists of ready-to-be-eaten foods in unopened packaging. Regarding individual packaging, each individually packaged food item counts as one. For example, if there is an opened bag originally holding twenty individually packaged crackers, and only three crackers remain, and if the individual packages of those three crackers have not been opened, they each count as B1. Never packaged or packaged but opened ready-to-be-eaten foods, B2, refer to ready-to-be-eaten foods that are yet to be put on the plate (table), or one 
whole unit of food with no traces of eating. These include whole, individual pastry buns, sandwiches, etc.; if one bag originally had five pastry buns without individual packages, and only three remain in that bag, those three will each count as B2. If a ready-to-be-eaten item is contained in an opened packaging that does not function as a plate or a bowl (the packaging is intended for further storage), such as pickles and candies in opened packages, the item qualifies as B2. Boiled rice wrapped in cling film for storage for later use is B2.

Additionally, apostrophes following each primary letter category indicate drinks (e.g., $\mathbf{B}^{\prime}, \mathbf{C}^{\prime}$, etc.). We did not create subcategories for C: leftovers other than $\mathbf{C}^{\prime}$ (leftover drinks), as leftovers are usually discharged in a mixed state, and are very cumbersome to sort further.

Table 3. Detailed categories of the classification system and the levels system.

\begin{tabular}{|c|c|c|c|c|c|c|}
\hline & \multicolumn{5}{|c|}{ Level } & \multirow[b]{2}{*}{ Definition } \\
\hline & \multicolumn{5}{|c|}{3} & \\
\hline \multirow{12}{*}{$\begin{array}{l}\text { Food } \\
\text { waste }\end{array}$} & \multirow{9}{*}{$\begin{array}{l}\text { Avoidable } \\
\text { food waste }\end{array}$} & \multirow{7}{*}{$\begin{array}{l}\text { A/B } \\
\text { Unused } \\
\text { food }\end{array}$} & \multirow{4}{*}{ A Unused ingredients } & \multirow{2}{*}{\multicolumn{2}{|c|}{$\begin{array}{l}\text { A1 Unopened ingredients } \\
\text { A2w Whole unused } \\
\text { ingredients }\end{array}$}} & Unopened ingredients in packaging \\
\hline & & & & & & $\begin{array}{l}\text { Whole unused ingredients not in/without } \\
\text { packaging }\end{array}$ \\
\hline & & & & \multicolumn{2}{|c|}{ A2wf Home-grown vegetables } & $\begin{array}{l}\text { Large amounts of harvest that appears to be } \\
\text { home-grown such as with irregularities and } \\
\text { extensive stems. }\end{array}$ \\
\hline & & & & \multicolumn{2}{|c|}{ A2p Partly used ingredients } & $\begin{array}{l}\text { Partly used ingredients in or without } \\
\text { packaging }\end{array}$ \\
\hline & & & \multirow{3}{*}{$\begin{array}{l}\text { B Unused } \\
\text { ready-to-be-eaten } \\
\text { food }\end{array}$} & \multicolumn{2}{|c|}{$\begin{array}{l}\text { B1 Unopened } \\
\text { ready-to-be-eaten food }\end{array}$} & $\begin{array}{c}\text { Unopened ready-to-be-eaten food in } \\
\text { packaging including in unopened individual } \\
\text { packages }\end{array}$ \\
\hline & & & & \multicolumn{2}{|c|}{$\begin{array}{l}\text { B2 Uneaten ready-to-be-eaten } \\
\text { food }\end{array}$} & $\begin{array}{l}\text { Whole unused ready-to-be-eaten foods } \\
\text { without packaging, and partly unused } \\
\text { ready-to-be-eaten foods in packaging, } \\
\text { including food in plastic wrap assumably } \\
\text { intended for storage, such as steamed rice } \\
\text { wrapped in cling film. } \\
\text { However, obvious leftovers such as remains in } \\
\text { disposable lunchbox are classified into } \\
\text { leftovers even in packaging. }\end{array}$ \\
\hline & & & & \multicolumn{2}{|c|}{ B'Unopened drinks } & Unopened drinks in packaging \\
\hline & & \multirow{2}{*}{\multicolumn{2}{|c|}{ C Leftovers }} & & food & $\begin{array}{l}\text { Ready-to-be-eaten or cooked food that } \\
\text { appears to have been disposed after being } \\
\text { served and partially eaten. In principle, } \\
\text { without packaging. However, partially eaten } \\
\text { food left in packaging that is designed to serve } \\
\text { as plate/bowl (food that is designed to be } \\
\text { eaten directly from the packaging) also } \\
\text { qualifies as leftover food. }\end{array}$ \\
\hline & & & & & drinks & Leftover drinks in bottles or packaging \\
\hline & \multirow{3}{*}{$\begin{array}{l}\text { Non- } \\
\text { avoidable } \\
\text { food waste }\end{array}$} & \multirow{2}{*}{\multicolumn{3}{|c|}{ D Intentionally removed parts }} & $\begin{array}{l}\text { De Possibly } \\
\text { avoidable }\end{array}$ & $\begin{array}{c}\text { Intentionally removed parts that are } \\
\text { physically edible such as vegetable scraps, } \\
\text { meat fat, fish skin, cooking oil, bread crust and } \\
\text { kelp for soup stock. } \\
\text { However, vegetable waste such as corn cores, } \\
\text { which are clearly inedible and may have a } \\
\text { significant quantity, are classified into inedible } \\
\text { parts. }\end{array}$ \\
\hline & & & & & $\begin{array}{l}\text { Di Inedible } \\
\text { parts }\end{array}$ & $\begin{array}{c}\text { Intentionally removed parts that are } \\
\text { physically difficult to eat such as fruit scraps, } \\
\text { seeds, bones, eggshells, shells, used coffee } \\
\text { grounds and bagged soup stock. } \\
\text { However, fruit scraps which are clearly edible } \\
\text { and may have a significant quantity such } \\
\text { apple peels, are classified into "possibly } \\
\text { avoidable". }\end{array}$ \\
\hline & & & E Unclassifiable & & $\begin{array}{l}\text { E Unclassifi- } \\
\text { able }\end{array}$ & $\begin{array}{c}\text { Very fine food waste that gets caught in } \\
\text { kitchen sink strainers, or food waste blended } \\
\text { with non-food waste that is difficult to sort } \\
\text { further. }\end{array}$ \\
\hline
\end{tabular}

\subsubsection{Subcategories of Intentionally Removed Parts D}

We have defined intentionally removed and discarded parts of foods not commonly eaten ("intentionally removed parts") as food waste that does not constitute avoidable food waste. However, we will further classify these into De: possibly avoidable parts that are 
removed as they are not commonly eaten much or not eaten at all, and Di: inedible parts that are physically difficult to eat. For example, De consists of vegetable scraps, such as the skin and leaves of a daikon radish or skins of potatoes and carrots, while the brown skin of an onion, husks and bare cobs of corn, and the skins of taro count as Di. In general, fruit skins count as Di, although there are exceptions, such as apple skins, etc. Small amounts of such exceptional items can be neglected (following the general principle), but if there is a significant quantity, their potential edibility should be assessed and categorised respectively.

"De: possibly avoidable" is used when it is desired to include the edible parts of "D: intentionally removed parts" as avoidable or possibly avoidable food waste (If we were to incorporate "excessive removal" into avoidable food waste, in accordance with MAFF and the Ministry of the Environment's pre-existing definition, that may mean the inclusion of our "De: possibly avoidable" into avoidable food waste), or when it is desired to measure the effect of the diffusion of "eco-cooking", utilising peels and other potentially edible parts. However, it is rather time consuming to make individual decisions about whether an item falls under categories De or Di, since the boundary of edible and inedible parts of food is obscure by nature, as discussed in 2.1. Therefore, we recommend classifying $\mathbf{D}$ into De and Di only when we need to know their amounts.

\subsubsection{Category E: Unclassifiable}

E: unclassifiable refers to very fine food waste that gets caught in kitchen sink strainers, or food waste blended with non-food waste that is difficult to sort further. Efforts should be made to sort food waste into other categories as far as possible, and to limit the amount classified as E. In the final report of the survey, the percentage of "E: unclassifiable" and its treatment should be stated clearly (e.g., whether counted as avoidable or unavoidable food waste).

\subsubsection{Levels Scheme}

We suggest a five-levels scheme, according to the levels of detailed sorting, allocating subcategories to the four major categories. The appropriate level to choose, then, depends on the objectives and available budget for the survey. The default minimum classification is Level 3, which consists of the four basic categories plus "E: Unclassifiable", making five categories. However from our experience, we can say that it is easier to divide them into Level 4 categories. D is classified into De and Di only at level 5. The reason is as described in Section 3.2.2.

\subsection{Procedure of the Food Waste Sorting Analysis}

The main emphasis of this paper is on categorisation. An overview of the whole procedure of sorting analysis is shown in Appendix A. Regarding the source of sample waste for sorting, as it is a common practice in Japan to dispose of food waste as burnable waste in municipal waste management; burnable waste will be the subject of sorting analysis, unless there is a separate collection for food (organic) waste. It is essential to transport the sampled waste on a flat loader vehicle, as waste becomes difficult to sort if it is mixed and compacted in a waste collection vehicle.

Since the conception of this methodology, the authors have applied it to several actual sorting analyses in Japan. In this paper, the results from Setagaya, Kodaira, Koganei and district X in Tokyo Metropolitan Prefecture, Kawaguchi (Saitama Pref.), Seika (Kyoto Met. Pref.), and Nagai (Yamagata Pref.) are introduced and compared. Some of the sorting analyses were the authors' own initiative, some were conducted by the local authority as part of research for preparing a local waste plan. The sample waste was gathered from waste collection points with dedicated flat loader trucks, on routine collection days before the usual collection vehicle came around. The results of each waste sorting analysis are shown in Table 4 in Section 4.1.1. 
Table 4. Results of the household food waste sorting analyses.

\begin{tabular}{|c|c|c|c|c|c|c|c|c|c|c|}
\hline \multirow{2}{*}{\multicolumn{3}{|c|}{$\begin{array}{c}\text { Place of Analysis } \\
\text { Housing Types }\end{array}$}} & \multicolumn{2}{|c|}{ Koganei } & \multirow{2}{*}{\multicolumn{2}{|c|}{$\begin{array}{c}\text { District X } \\
\text { Mixed }\end{array}$}} & \multicolumn{4}{|c|}{ Setagaya } \\
\hline & & & \multirow{2}{*}{$\begin{array}{c}\text { Detached } \\
\text { June } 19\end{array}$} & \multirow{2}{*}{$\begin{array}{c}\text { Flats single } \\
\text { July } 19\end{array}$} & & & Detached & Flats & Detached & Flats \\
\hline & ate of Analysis & & & & December 18 & July 18 & \multicolumn{2}{|c|}{ January 21} & \multicolumn{2}{|c|}{ August 19} \\
\hline \multicolumn{3}{|c|}{ Total Sample Waste [kg] } & 181 & 133 & 82 & 70 & 259 & 258 & 54 & 77 \\
\hline \multicolumn{3}{|c|}{ Percentage of Food Waste [\%] } & 44.8 & 25.9 & 41.5 & 44.3 & 27.3 & 21.4 & 27.3 & 34.7 \\
\hline & category & sub-category & \multicolumn{8}{|c|}{ percentages of each subcategory within food waste } \\
\hline \multirow{4}{*}{\multicolumn{2}{|c|}{$\begin{array}{l}\text { A: unused } \\
\text { ingredients }\end{array}$}} & A1:unopened & 2.5 & 11.6 & 3.6 & \multirow{3}{*}{7.0} & 4.1 & 7.6 & 8.6 & 7.8 \\
\hline & & A2w:whole & 3.3 & 6.2 & 3.2 & & 3.2 & 2.9 & 0.3 & 7.1 \\
\hline & & $\begin{array}{l}\text { A2wf:home } \\
\text { grown }\end{array}$ & 0.0 & 0.0 & 0.0 & & 0.0 & 0.0 & 0.0 & 0.0 \\
\hline & & $\begin{array}{c}\text { A2p:partly } \\
\text { used }\end{array}$ & 6.0 & 10.0 & 3.6 & 5.9 & 7.2 & 13.0 & 4.1 & 9.2 \\
\hline \multirow{3}{*}{$\begin{array}{c}\text { Avoidable Food } \\
\text { Waste }\end{array}$} & \multirow{3}{*}{$\begin{array}{l}\text { B:unused } \\
\text { ready to be } \\
\text { eaten food }\end{array}$} & B1:unopened & 3.1 & 6.2 & 2.8 & 3.4 & 4.6 & 6.2 & 0.9 & 4.2 \\
\hline & & $\begin{array}{c}\text { B2:partly } \\
\text { used }\end{array}$ & 0.2 & 0.0 & 2.6 & 1.4 & 5.6 & 1.9 & 0.5 & 0.0 \\
\hline & & $\mathrm{B}^{\prime}$ :drinks & 0.0 & 1.5 & 0.0 & 0.0 & 0.5 & 1.4 & 0.0 & 5.0 \\
\hline \multirow{2}{*}{$\begin{array}{c}\text { Non-avoidable } \\
\text { FW }\end{array}$} & \multirow{2}{*}{$\begin{array}{c}\text { D:intentionally } \\
\text { removed }\end{array}$} & De:edible & 19.0 & 12.4 & 21.8 & 12.6 & 23.2 & 17.1 & 29.5 & 20.4 \\
\hline & & Di:inedible & 40.8 & 15.8 & 46.0 & 54.4 & 33.9 & 24.5 & 31.4 & 23.7 \\
\hline \multicolumn{3}{|c|}{ E: Unsortably Mixed Food Waste } & 7.6 & 9.3 & 1.3 & 5.4 & 0.2 & 0.0 & 4.3 & 9.9 \\
\hline
\end{tabular}


Table 4. Cont.

\begin{tabular}{|c|c|c|c|c|c|c|c|c|c|c|c|}
\hline \multirow{2}{*}{\multicolumn{3}{|c|}{$\begin{array}{c}\text { Place of Analysis } \\
\text { Housing Types }\end{array}$}} & \multirow{3}{*}{\begin{tabular}{|c|} 
Kodaira \\
Mixed \\
February 21 \\
\end{tabular}} & \multicolumn{3}{|c|}{ Nagai } & \multirow{2}{*}{\multicolumn{2}{|c|}{$\begin{array}{c}\text { Seika } \\
\text { Detached }\end{array}$}} & \multicolumn{3}{|c|}{ Kawaguchi } \\
\hline & & & & Total & $\begin{array}{c}\text { Mixed } \\
\text { Burnable }\end{array}$ & Food Waste & & & $\begin{array}{c}\text { New } \\
\text { Detached }\end{array}$ & $\begin{array}{c}\text { Old } \\
\text { Detached }\end{array}$ & Flats \\
\hline \multicolumn{3}{|c|}{ Date of Analysis } & & \multicolumn{3}{|c|}{ March 20} & December 19 & December 18 & \multicolumn{3}{|c|}{ August 19} \\
\hline \multicolumn{3}{|c|}{ Total Sample Waste $[\mathrm{kg}]$} & 415 & 1507 & 1130 & 376 & 300 & 306 & 104 & 105 & 97 \\
\hline \multicolumn{3}{|c|}{ Percentage of Food Waste [\%] } & 33.5 & 40.1 & 21.6 & 99.0 & 50.4 & 44.8 & 27.8 & 32.3 & 37.9 \\
\hline & category & sub-category & \multicolumn{9}{|c|}{ percentages of each subcategory within food waste } \\
\hline \multirow{8}{*}{$\begin{array}{l}\text { Avoidable Food } \\
\text { Waste }\end{array}$} & \multirow{4}{*}{$\begin{array}{l}\text { A: unused } \\
\text { ingredients }\end{array}$} & A1:unopened & 5.1 & 2.2 & 5.5 & 0.0 & 4.9 & \multirow{2}{*}{12.2} & 6.4 & 10.4 & 2.6 \\
\hline & & A2w:whole & 2.0 & 6.4 & 7.2 & 5.8 & 8.0 & & 7.4 & 2.8 & 6.2 \\
\hline & & $\begin{array}{c}\text { A2wf:home } \\
\text { grown }\end{array}$ & 1.4 & 10.7 & 2.2 & 16.3 & 2.4 & 5.9 & 0.5 & 0.0 & 0.0 \\
\hline & & $\begin{array}{c}\text { A2p:partly } \\
\text { used }\end{array}$ & 7.8 & 6.8 & 8.7 & 5.5 & 13.6 & 10.4 & 5.8 & 4.5 & 9.1 \\
\hline & \multirow{2}{*}{$\begin{array}{l}\text { B:unused } \\
\text { ready to be } \\
\text { eaten food }\end{array}$} & B1:unopened & 1.8 & 1.3 & 3.2 & 0.0 & 3.7 & \multirow[b]{2}{*}{2.8} & 9.8 & 5.2 & 2.6 \\
\hline & & $\begin{array}{c}\text { B2:partly } \\
\text { used }\end{array}$ & 1.5 & 3.8 & 5.6 & 2.6 & 4.1 & & 4.9 & 4.4 & 4.4 \\
\hline & \multirow{2}{*}{ C:leftovers } & C:food & 9.2 & 12.9 & 13.0 & 12.9 & 13.7 & \multirow{2}{*}{19.2} & 20.6 & 15.4 & 25.1 \\
\hline & & $C^{\prime}$ :drinks & 0.0 & 0.1 & 0.1 & 0.0 & 0.1 & & 1.0 & 0.5 & 0.4 \\
\hline \multirow{2}{*}{$\begin{array}{c}\text { Non-avoidable } \\
\text { FW }\end{array}$} & \multirow{2}{*}{$\begin{array}{l}\text { D:intentionally } \\
\text { removed }\end{array}$} & De:edible & \multirow{2}{*}{71.0} & 33.7 & 22.5 & 41.1 & 23.1 & 19.5 & 20.2 & 17.5 & 15.1 \\
\hline & & Di:inedible & & 20.0 & 29.4 & 13.8 & 24.3 & 27.4 & 18.4 & 25.4 & 31.0 \\
\hline \multicolumn{3}{|c|}{ E: Unsortably Mixed Food Waste } & 0.0 & 2.2 & 2.5 & 2.1 & 2.4 & 2.7 & 5.0 & 3.2 & 3.6 \\
\hline
\end{tabular}




\section{Results and Discussion}

\subsection{Remarks on the Composition of Food Waste}

\subsubsection{Results of Sorting Analyses}

We were able to put into practise the method suggested in this paper. The results of such sorting analysis of household food waste are shown in this section. Sample size varied: earlier analyses in Setagaya and district $X$ took place as development and feasibility testing of the methodology, and involved a small sample. Later samples involve samples of more than $200 \mathrm{~kg}$. As we can see from the results below, there were no outlier results; it seems possible to generate a stable result even with a relatively small sample.

Here only the sorting results of the burnable waste fraction are shown, as food waste contained in other separate collection fractions can be considered negligibly small. The exception is Nagai City, where separate collection of food waste has been implemented. In the central part of Nagai City, food waste is collected separately and composted. Waste sampled at each of the 21 sampling collection points was analysed separately for segregated food waste and for burnable waste. The municipality collects sorted food waste in large containers as shown in Figure 2. The accuracy of the separation was very high and none of the packaging from A1 and B1 (food in original packaging) was found. We could demonstrate that even if the food waste was collected separately with the packaging removed thoroughly, a level 5 classification was still possible.

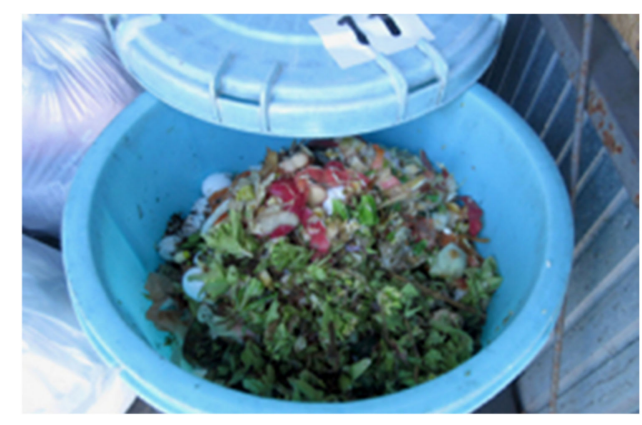

Figure 2. Separated food waste in Nagai.

Table 4 and Figures 3 and 4 show the results. Figure 3 shows the composition of the total food waste, including non-avoidable parts, while Figure 4 shows the breakdown within avoidable food waste (categories A, B and C). These sorting analyses took place between July 2018 and February 2021. The level of detail in these analyses was not the same. For example, in Seika Town in December 2018, some subcategories in A and B were not separated. A large part of what is now classified as subcategory B2 was included in category C (the definitions of subcategories were revised in August 2019, following discussions after the initial sorting analyses). At Kodaira City in February 2021, sorting was done at Level 4 , which does not classify category D into subcategories.

The percentages of total food waste, including non-avoidable, among total waste in our case studies ranged from $21.4 \%$ to $50.4 \%$ with an average of $35.6 \%$. In fiscal 2020 , the Ministry of Environment [16] provided subsidies for sorting analyses on food waste in 18 cities in Japan, and their average was $33.7 \%$, ranging from $23.1 \%$ to $46.4 \%$. The percentages of avoidable food waste within total food waste in our cases had a range of $27.5 \%$ to $62.5 \%$ and an average of $44.0 \%$, while the Ministry of Environment figures were in the range of $18.5 \%$ to $53.5 \%$ and had an average of $36.2 \%$. Potentially edible preparation residues are excluded in these figures, in our case, category De, and in the Ministry's case "excessive removal". The definition of total food waste is more or less the same between us and the Ministry, and there was not much difference in the results. On the other hand, the definition of avoidable food waste is expressed somewhat differently, and our results appear to be slightly higher. Our case studies have a wider range, as they show results of 
different housing types separately. In the ministry's cases, the figures represent each city with a mixture of housing types. Further discussion on the results is shown in Appendix B.

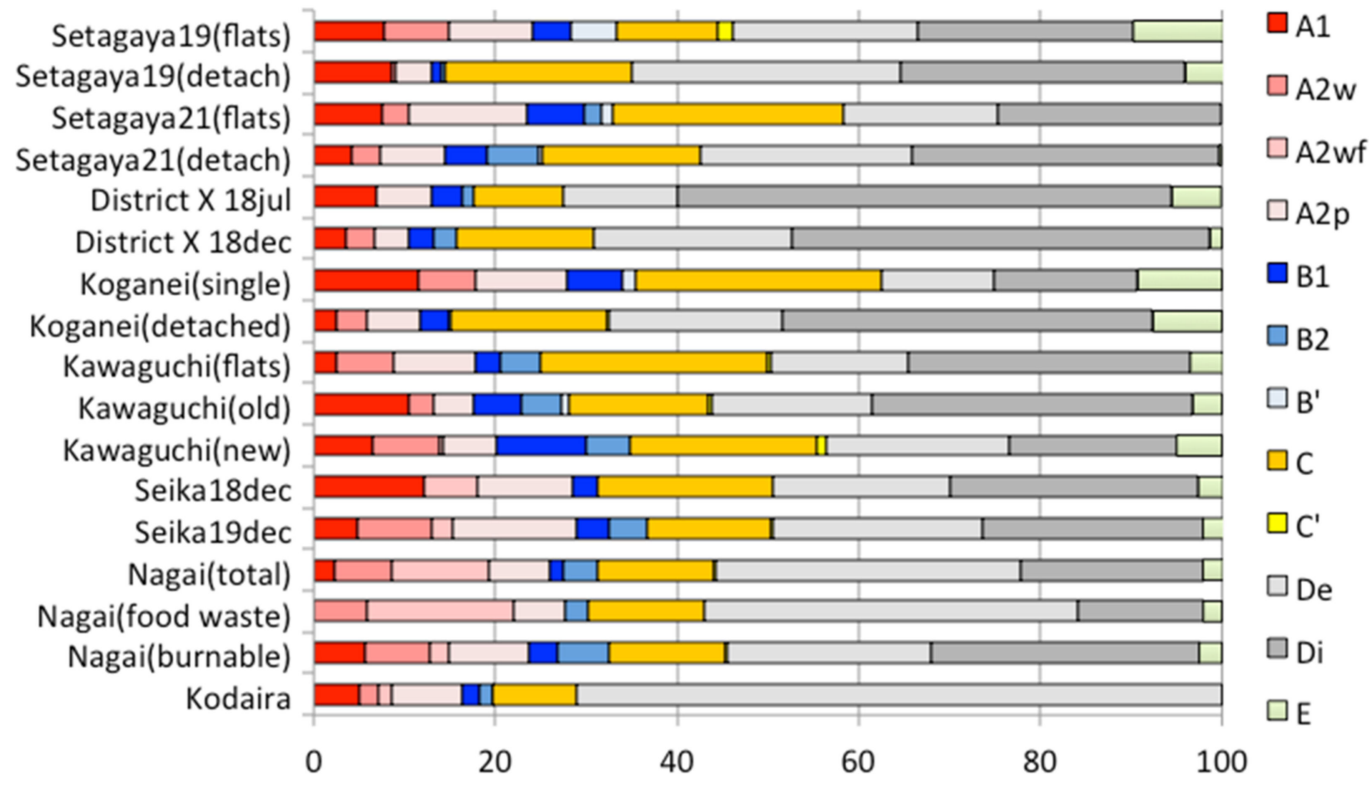

Figure 3. Results of the household food waste sorting analyses.

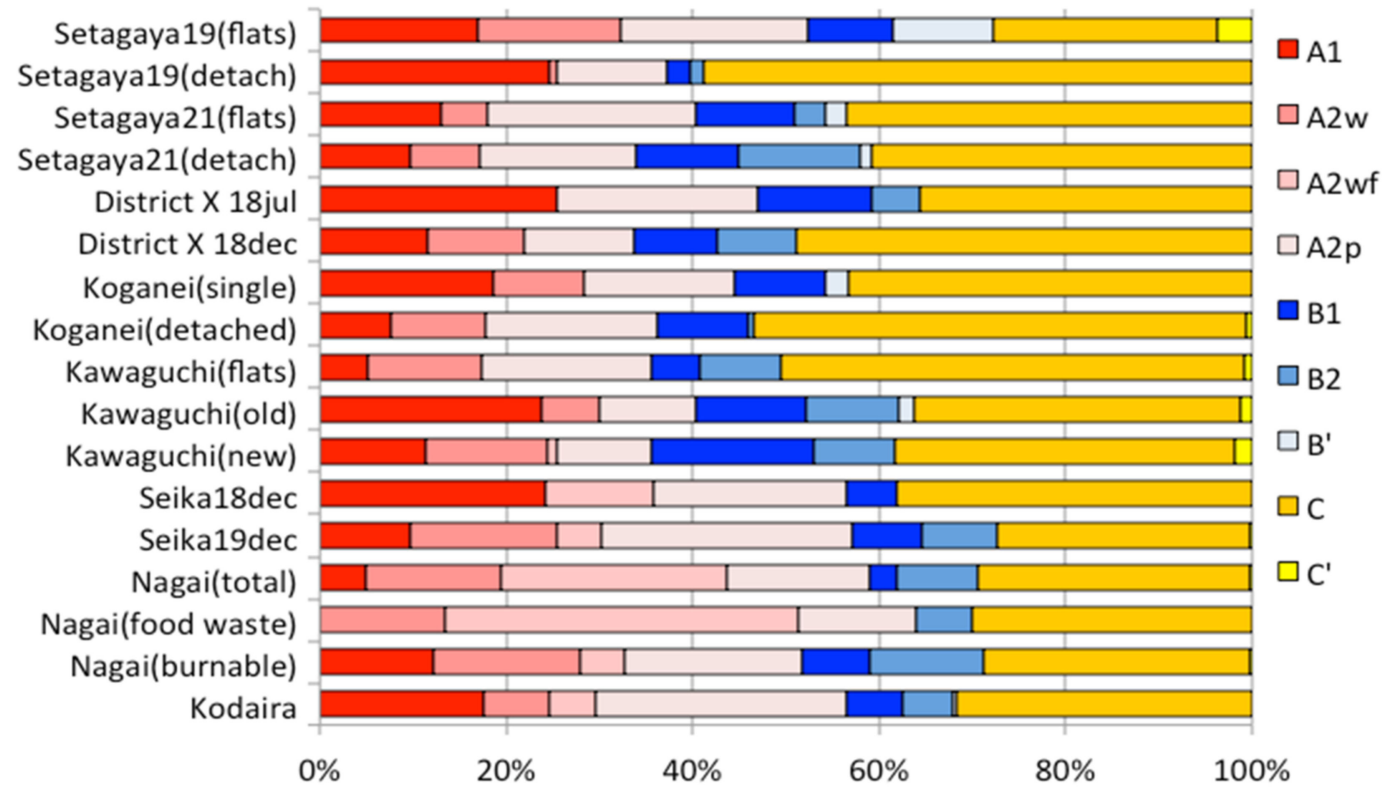

Figure 4. Proportion of categories within avoidable food waste.

\subsubsection{Policy Implications from the Sorting Analysis Results}

Figure 4 shows that the proportions of A, B and C vary among municipalities and areas, suggesting that the prioritisation of targets should reflect regional characteristics. In the case of municipalities with a high percentage of category A, priority should be given to promoting prevention of the generation of A. For example, the following policies can be considered: a campaign to promote the habit of organising the contents in the refrigerators as to prevent food from being left forgotten and to optimise the amount of food purchased; awareness-raising activities to promote an appropriate understanding of "best-before" dates and the shelf life of food, to use the most perishable ones first and to prevent food from being disposed of just because it has passed this date; and the dissemination of 
know-how on how to preserve foodstuffs, so as to prolong the life of unused ingredients. Acceptance of the suggested behaviours and the effectiveness of the policies will need to be examined first, but once the target behaviours are identified, the measures to focus on will become clearer. It should be noted that areas with a large amount of A2wf will need to consider whether A should be the primary target for prevention, as the cause of $\mathrm{A} 2 \mathrm{Wf}$ is different from other items in category A.

Recommendations for areas with a high proportion of $B$ would be to consider awarenessraising activities about the perishability of ready-to-eat foods and the shelf life of preserved foods, as well as the promotion of the rolling stock method for emergency supplies, whereby people consume such items in their daily living and replace them before the expiry dates. For areas with a high percentage of $C$, it will be useful to suggest practical methods for estimating appropriate portion sizes. Suggestions of "remake" recipes making use of leftover dishes may also be effective. The waste sorting analysis proposed in this study will help with identifying which measures should be prioritised for each region.

\subsection{Ease of Understanding and International Applicability}

\subsubsection{Acceptance in Japan}

As mentioned in our second criteria for desirable sorting analyses, the classification scheme must be intuitively easy to understand, both for conducting the analyses as staff members, and for understanding their results as policy-makers and as the general public. The common thread that emerges from the experience of these surveys is that the sorting staff's understanding of the classification was sufficient and did not cause any major confusion. In the case of Kodaira, it took about $2.5 \mathrm{~h}$ for $10 \mathrm{staff}$ members to sort $140 \mathrm{~kg}$ of food waste. In the 2021 Setagaya analysis, we managed to complete the sorting analysis for two locations in one day (each with ca. $260 \mathrm{~kg}$ of sampled household waste, including $70 \mathrm{~kg}$ and $55 \mathrm{~kg}$ of food waste, respectively), also with a staff of about 10 people. In some cases, recruited staff members were students who had previously never experienced a sorting analysis. In the debriefing session for the analyses in District $X$, the 15 students who undertook the work commented that they found the classification scheme relatively easy to understand. Judging from the progress of work and the responses of staff, it could be said that the proposed classification is straightforward and not difficult to understand, thus satisfying criteria (2).

\subsubsection{International Consideration in the Development Phase}

In the development stages of our proposed classification scheme, we have surveyed existing literature worldwide regarding sorting analyses focusing on food waste, and gathered information on categorisations adopted in those studies. The prototype proposal was presented for consultation to experienced researchers at the Institute of Waste Management, BOKU University Vienna (ABF-BOKU), Agricultural Economics Department at Bologna University, and the Faculty of Environment and Engineering at the University of Southampton. Moreover, we invited members of ABF-BOKU to Tokyo in August 2019, and they took part in the sorting process for the case described as "Setagaya19" in the section above. An intensive debriefing session took place after the sorting and weighing process, including a discussion on the possibility of applying the classification scheme to sorting analyses in Austria. Several adjustments and refinements were made to the definition of subcategories, reflecting the outcome of the session, to accommodate the differences in retail, cooking, and eating customs in Japan and Austria. We decided to suggest a levels-based scheme on the extent of detailed subcategories, which is also introduced in the guideline for household waste-sorting analyses in Austria [17]. The classification scheme described in this paper is a result of such discussion. In this way, we made sure that the basic concept of the categorisation is internationally acceptable. 


\subsubsection{Classification Workshops with Photo Samples}

We also tested whether the concepts of our categories were easy to understand worldwide, within a wide range of people with different cultural and professional backgrounds. We also wanted to see to what extent each individual items would be classified in the same category, following the shared concept.

As it is difficult to use real waste samples at indoor conferences and meetings, we decided to use photos of food waste items found in analyses conducted earlier. This method was inspired by an earlier workshop conducted by Schneider [18]. About 35 items were selected, including "tricky" items that can fall under different categories, depending on the way one thinks about them.

The participants of the workshops are asked to sort the photos into the abovementioned A, B, C, De, and Di categories, after a brief explanation of the classification scheme by the facilitator. We preferred to set this up as group work, with groups consisting of people with different backgrounds, as that would trigger discussions and deeper considerations among the participants. The authors conducted this workshop on many occasions, such as international academic or professional conferences (e.g., Sardinia 2019, Meeting of Agricultural Chief Scientists of G20) (Figure 5), seminars for international students (e.g., Keio University Japan, University of Cambridge UK), as well as at staff briefings, before conducting sorting analyses based on this classification.

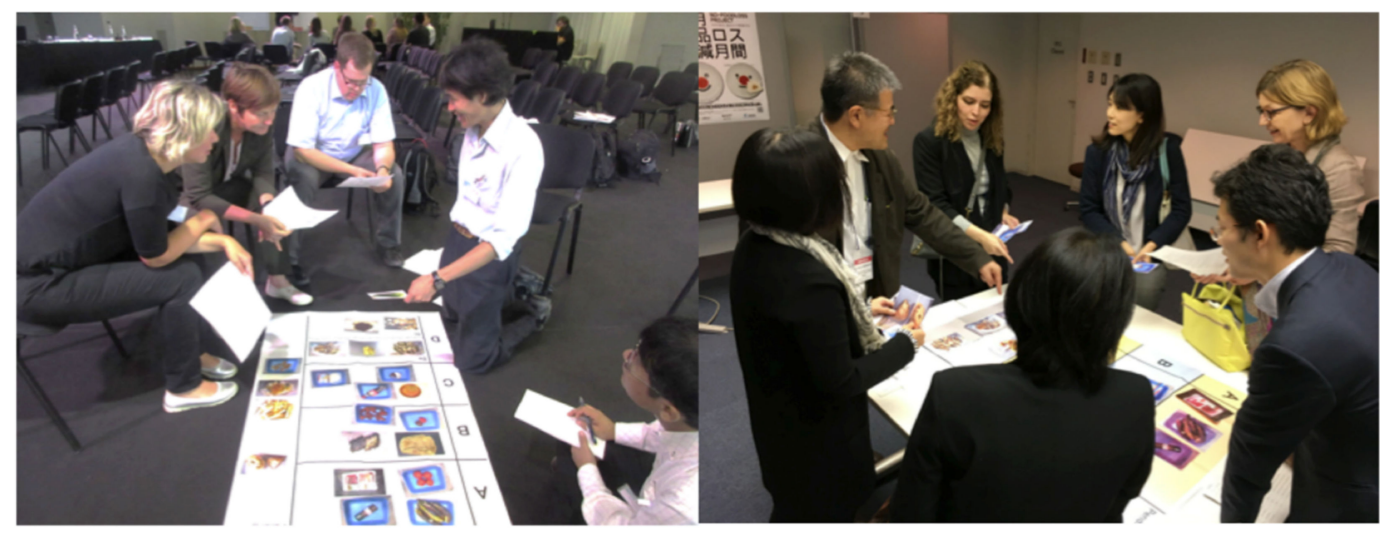

Figure 5. Photos of workshops.

Results from about 20 groups from the workshops, excluding those aimed for training of sorting staff are summarised in Table 5. The workshops include participants worldwide, covering all continents and from both developed and less developed economies. For many items, such as raw meat packaged in plastic trays and wrap, there was unanimous agreement (in this case, category " $\mathrm{A}$ "). This implied that the basic concepts of our proposed sorting categories are universally agreeable.

Although the results indicated that there is a common understanding regarding the basic concepts of categorisation, there were discrepancies for the placement of some individual items. For certain items, there was disagreement on whether they fall under "De" or "Di". To a lesser extent, there were also cases of disagreement between "A" and "De". The main factor for this is the difference in food customs in the former case, and awareness or tolerance of food waste in the latter. By 'tolerance' we mean an individual's value of whether he or she would allow the food item (or part of it) to be thrown away without pointing out that it could have been avoided.

We consider that for these items, it is not feasible to establish a universal standard with concrete examples. As long as the basic concepts of the proposed scheme are shared, suitable standards for individual items can be set for each country, following each basic concept and reflecting local customs and situations. 
Table 5. Results of the photo-sorting workshops.

\begin{tabular}{|c|c|c|c|c|c|c|c|c|c|c|c|c|c|c|c|c|c|}
\hline \multirow{3}{*}{ item } & \multirow{3}{*}{ tendency } & \multirow{2}{*}{\multicolumn{2}{|c|}{$\begin{array}{c}\text { Sardinia } \\
\text { October } 19\end{array}$}} & \multicolumn{6}{|c|}{ MACS G20 Tokyo WS } & \multicolumn{4}{|c|}{ Keio Uni } & \multicolumn{3}{|c|}{ Cambridge U. } & \multirow{3}{*}{$\begin{array}{c}\text { Chuo } \\
\text { May } \\
20\end{array}$} \\
\hline & & & & \multicolumn{6}{|c|}{ October 19} & \multicolumn{4}{|c|}{ December 19} & \multicolumn{3}{|c|}{ February 20} & \\
\hline & & 1 & 2 & 1 & 2 & 3 & 4 & 5 & 6 & 1 & 2 & 3 & 4 & 1 & 2 & 3 & \\
\hline raw meat in unopened packaging & unanimous $\mathrm{A}$ & A & A & A & A & A & A & A & A & A & A & A & A & A & B & A & $\mathrm{A}$ \\
\hline mini tomatoes (4pcs) & unanimous $\mathrm{A}$ & A & A & B & A & A & A & A & A & A & A & A & A & A & A & A & A \\
\hline banana (overripe) & mostly A & A & A & B & A & A & A & B & B & A & A & De & A & A & B & A & $\mathrm{P}$ \\
\hline chilli pepper power (partly used) & unanimous $\mathrm{A}$ & A & A & A & B & A & A & A & A & A & A & A & A & A & A & A & A \\
\hline onion (cut/raw) & mostly A & A & A & De & A & A & B & A & B & A & A & C & A & $\mathrm{C}$ & $\mathrm{De}$ & C & A \\
\hline green part of leek & mostly A (De) & De & A & $\mathrm{De}$ & A & $\mathrm{AD}$ & $\mathrm{De}$ & $\mathrm{P}$ & A & A & A & A & A & A & A & A & A \\
\hline daikon (raddish) leaves & A or De & $\mathrm{Di}$ & De & A & $\mathrm{P}$ & $\mathrm{AD}$ & $\mathrm{De}$ & $\mathrm{P}$ & A & A & A & A & A & De & $\mathrm{De}$ & De & A \\
\hline easter egg & $A$ or $B$ & B & B & C & B & $\mathrm{B}$ & $\mathrm{C}$ & B & A & $\mathrm{B}$ & A & A & A & A & A & A & A \\
\hline grilled chicken wings (uneaten) & mostly B & B & B & B & B & $\mathrm{BC}$ & $\mathrm{C}$ & B & B & B & B & B & $\mathrm{P}$ & B & C & B & B \\
\hline crepes (several pieces) & mostly B & B & B & B & B & C & $\mathrm{C}$ & B & $\mathrm{B}$ & B & $\mathrm{C}$ & B & $\mathrm{P}$ & B & $\mathrm{C}$ & B & $\mathrm{C}$ \\
\hline spare ribs (burned) & mostly B & B & B & Di & B & $\mathrm{BD}$ & $\mathrm{C}$ & C & B & B & B & B & B & B & $\mathrm{C}$ & B & B \\
\hline fried egg (no bite marks) & $\mathrm{B}$ or C & B & B & $\mathrm{C}$ & B & C & $\mathrm{C}$ & C & $\mathrm{C}$ & B & $\mathrm{C}$ & B & B & B & $\mathrm{C}$ & B & $\mathrm{C}$ \\
\hline macaroni salad (partly used in packaging) & $\mathrm{B}$ or C & $\mathrm{C}$ & $\mathrm{BC}$ & B & $\mathrm{C}$ & $\mathrm{C}$ & B & C & $\mathrm{C}$ & B & B & C & A & $\mathrm{C}$ & B & $\mathrm{C}$ & C \\
\hline cooked pasta (partly eaten, in packaging) & unanimous C & $\mathrm{C}$ & $\mathrm{C}$ & $\mathrm{C}$ & $\mathrm{C}$ & $\mathrm{C}$ & $\mathrm{C}$ & $\mathrm{C}$ & $\mathrm{C}$ & $\mathrm{C}$ & $\mathrm{C}$ & $\mathrm{C}$ & $\mathrm{C}$ & $\mathrm{C}$ & C & $\mathrm{C}$ & $\mathrm{C}$ \\
\hline Coca Cola in bottle (partly finished) & unanimous C & $\mathrm{C}$ & $\mathrm{C}$ & $\mathrm{C}$ & $\mathrm{C}$ & $\mathrm{C}$ & $\mathrm{C}$ & C & $\mathrm{C}$ & $\mathrm{C}$ & $\mathrm{C}$ & C & $\mathrm{C}$ & $\mathrm{C}$ & B & $\mathrm{C}$ & C \\
\hline fruit jelly (partly finished, in packaging) & unanimous C & $\mathrm{C}$ & $\mathrm{C}$ & $\mathrm{C}$ & $\mathrm{C}$ & $\mathrm{C}$ & $\mathrm{C}$ & C & $\mathrm{C}$ & $\mathrm{C}$ & B & C & $\mathrm{C}$ & $\mathrm{C}$ & B & $\mathrm{C}$ & C \\
\hline outer crust of pizza (bitten off) & mostly C(De) & $\mathrm{C}$ & De & $\mathrm{C}$ & $\mathrm{C}$ & $\mathrm{C}$ & $\mathrm{C}$ & $\mathrm{P}$ & $\mathrm{C}$ & De & $\mathrm{De}$ & De & $\mathrm{C}$ & $\mathrm{C}$ & $\mathrm{C}$ & C & C \\
\hline apple (core with some flesh) & mostly De & De & $\mathrm{CD}$ & $\mathrm{P}$ & Cde & C & De & $\mathrm{P}$ & C & De & $\mathrm{De}$ & De & C & De & $\mathrm{C}$ & De & D \\
\hline crust of toast bread (cut off) & mostly De & $\mathrm{De}$ & De & De & $\mathrm{P}$ & $C D$ & $\mathrm{De}$ & $\mathrm{P}$ & De & $\mathrm{De}$ & $\mathrm{De}$ & De & $\mathrm{P}$ & A & C & A & C \\
\hline carrot peel & mostly De & $\mathrm{P}$ & $\mathrm{P}$ & $\mathrm{De}$ & De & $\mathrm{Di}$ & $\mathrm{Di}$ & De & De & De & $\mathrm{De}$ & De & De & De & De & $\mathrm{De}$ & De \\
\hline broccoli stem & mostly De & $\mathrm{Di}$ & $\mathrm{P}$ & De & $\mathrm{P}$ & Dei & $\mathrm{P}$ & $\mathrm{P}$ & De & $\mathrm{Di}$ & $\mathrm{De}$ & De & $\mathrm{P}$ & De & $\mathrm{De}$ & $\mathrm{De}$ & De \\
\hline apple peel & mostly De & $\mathrm{De}$ & De & $\mathrm{De}$ & Dei & Dei & De & $\mathrm{P}$ & De & $\mathrm{De}$ & $\mathrm{De}$ & De & De & $\mathrm{De}$ & $\mathrm{De}$ & De & De \\
\hline potato peel & mostly De & De & $\mathrm{P}$ & $\mathrm{De}$ & Dei & Dei & $\mathrm{Di}$ & $\mathrm{P}$ & De & $\mathrm{Di}$ & $\mathrm{De}$ & De & De & De & $\mathrm{De}$ & De & D \\
\hline chicken skin and bone & De or Di & $\mathrm{De}$ & Dei & Di & De & Dei & $\mathrm{Di}$ & $\mathrm{P}$ & De & De & $\mathrm{Di}$ & $\mathrm{Di}$ & $\mathrm{Di}$ & $\mathrm{De}$ & $\mathrm{Di}$ & De & $\mathrm{D}$ \\
\hline cotfee grounds & unanimous Di & $\mathrm{Di}$ & $\mathrm{Di}$ & Di & $\mathrm{Di}$ & $\mathrm{Di}$ & $\mathrm{Di}$ & $\mathrm{Di}$ & Di & $\mathrm{Di}$ & $\mathrm{Di}$ & $\mathrm{Di}$ & Di & $\mathrm{Di}$ & $\mathrm{Di}$ & $\mathrm{Di}$ & $\mathrm{Di}$ \\
\hline egg shells & unanimous Di & $\mathrm{Di}$ & $\mathrm{Di}$ & $\mathrm{Di}$ & $\mathrm{Di}$ & Di & $\mathrm{Di}$ & $\mathrm{Di}$ & $\mathrm{Di}$ & $\mathrm{Di}$ & $\mathrm{Di}$ & $\mathrm{Di}$ & $\mathrm{Di}$ & $\mathrm{Di}$ & $\mathrm{Di}$ & $\mathrm{Di}$ & $\mathrm{Di}$ \\
\hline Temon wedges & varied & $\mathrm{P}$ & $\mathrm{P}$ & A & $\mathrm{P}$ & C & $\mathrm{Di}$ & $\mathrm{P}$ & B & A & $\mathrm{De}$ & C & $\mathrm{P}$ & C & $\mathrm{C}$ & C & C \\
\hline
\end{tabular}

(A, B, C, De, Di correspond to the categories. P indicates pending (undecided) at the end of workshop).

\subsection{Practical Implications of This Study}

We consider that the most distinct outcome of this study is that we managed to propose an internationally feasible and adoptable basis for the distinction between avoidable and non-avoidable parts in a waste sorting analysis.

It has been pointed out that it could be difficult to draw a line between edible and inedible food waste in the international context, due to differences in food customs around the world. This was also observed in our international workshops, where the most contentious disagreement among the participants was the distinction between categories $\mathrm{De}$ and $\mathrm{Di}$, i.e., whether a part that appears to be intentionally removed is potentially avoidable.

This was primarily solved by (a) making clear the concept of each main category (A,B,C, as mentioned above) of avoidable food waste, and (b) setting a category "intentionally removed parts", whereby "possibly avoidable" food waste (potentially edible preparation residues) was excluded from the definition of avoidable food waste.

Results of sorting analyses will be comparable, as long as items with the same positioning in each society are classified in the same way around the world. Therefore, when sorting food waste based on this classification method, we would like to see researchers in each region customise the given specific examples of foods to suit the local conditions.

As for enhancing practicality, we suggested a levels system, whereby the organiser of a sorting analysis can choose to which level of detail the sampled food waste should be sorted, depending on the analysis' purpose and availability of workforce. We found that the basic level (Level 3: A, B, and C) could be agreed upon widely and could be easily sorted. Even for the most detailed level (Level 5: A1, A2w, A2wf, A2p, B1, B2, B', C, C', $\mathrm{De}, \mathrm{Di}, \mathrm{E})$, it was found that clarifying to the sorting staff the examples of foods that fall under each classification item in the briefing helped eliminate confusion during the sorting analysis. As in the mentioned case studies, we have managed to sort as much as $150 \mathrm{~kg}$ of food waste into level 5 subcategories in 2-3 h with about 10 workers; we consider that the methodology is practical and is not excessively complicated.

Regarding the future development of this work, as we have successfully implemented a few sorting analysis in Japan based on the proposed methodology, we would then like to apply it in other parts of the world. Although we have made sure that the concepts are internationally acceptable, there may be a need for minor fixes for a smooth application worldwide. We can also conduct sorting analyses before and after a social intervention aiming to reduce food waste at households and assess its efficacy. 
With an accumulation of such results that are internationally comparable, we will be able to identify which policies and measures for food waste reduction are effective under which conditions.

\section{Concluding Remarks}

In this paper, we have described concepts for sorting analyses aimed at informing policies to prevent household food waste, in order to achieve the aims of SDGs. In order to provide useful information for prevention measures without entailing too much effort or cost, we concluded that preparation residues should be treated as one category, namely "intentionally removed", without dividing them into edible and inedible parts at the basic level of classification. We have proposed a sorting category table based on that, demonstrated its feasibility in actual sorting analyses, and indicated the potential for international adoption.

Regarding the concept, in Chapter 1, we introduced the following three criteria.

(1) It should be useful for proposing target behaviours/policies for prevention;

(2) It should make the concepts of categorisation clear and easy to understand;

(3) It should be practical and should not over-complicate the work of analysing the situation of food wastage.

The proposed classification was described in detail in Section 3. Regarding the first criterion above, it can be said that the classification enables us to suggest target behaviours and ways to prevent food waste at home. This classification corresponds to food flow in the home, and makes a distinction of category A, the ingredients/material for cooking, and category B, food that is already prepared to be eaten, as the main factors for their occurrence are different. The results of sorting analyses can be used to identify priorities for policy measures.

Regarding criterion (2), the definitions of the categories are clear and easy to understand with respect to the following two points, as explained in Section 4.2.

(1) Sorting staff, using this classification for the first time in a sorting analysis, could classify food waste without much confusion.

(2) When people from various parts of the world were asked to try the classification at several international workshops, the concept was correctly shared and there was no discrepancy in understanding, although there were some differences due to food culture and individual values, as shown in the results in Section 4.2.3. To circumvent issues caused by this, we defined "avoidable food waste" as categories A, B, and C, by their status within the flow of food items in the household. In international application, what is most important is not the unification of specific items belonging to each category, but a common understanding of the underlying concepts.

We hope that the framework for sorting analyses proposed in this paper will be adopted internationally to grasp the situation of household food waste. This will enable a proper grasp of the situation of food waste in one's own country as well as a proper international comparison on the situation of food waste. We believe that this will, in the end, contribute to devising effective measures for achieving SDG target 12.3 worldwide.

Author Contributions: Conceptualization, T.O., K.W. and H.Y.; Data curation, T.O., K.W. and H.Y.; Formal analysis, T.O., K.W. and H.Y.; Funding acquisition, T.O., K.W. and H.Y.; Investigation, T.O., K.W. and H.Y.; Methodology, T.O., K.W. and H.Y.; Project administration, T.O., K.W. and H.Y.; Visualization, T.O., K.W. and H.Y.; Writing-original draft, T.O., K.W. and H.Y.; Writing-review \& editing, T.O., K.W. and H.Y. All authors have read and agreed to the published version of the manuscript.

Funding: This research was funded by the Environment Research and Technology Development Fund (JPMEERF20183005).

Acknowledgments: This research was conducted together with our international collaborators, namely Felicitas Schneider (Thünen Institute), Gudrun Obersteiner, Silvia Scherhofer, Anna Happenhofer (BOKU University Vienna), Matteo Vittuari, Silvia Gaiani (University of Bologna), Ian Williams, 
Peter Shaw (University of Southampton). We are grateful to all those who cooperated in our research activities, including but not limited to participants of workshops and sorting analyses.

Conflicts of Interest: The authors declare no conflict of interest. The funders had no role in the design of the study; in the collection, analyses, or interpretation of data; in the writing of the manuscript, or in the decision to publish the results.

\section{Appendix A}

Table A1. Procedure of sorting analysis (example).

Step

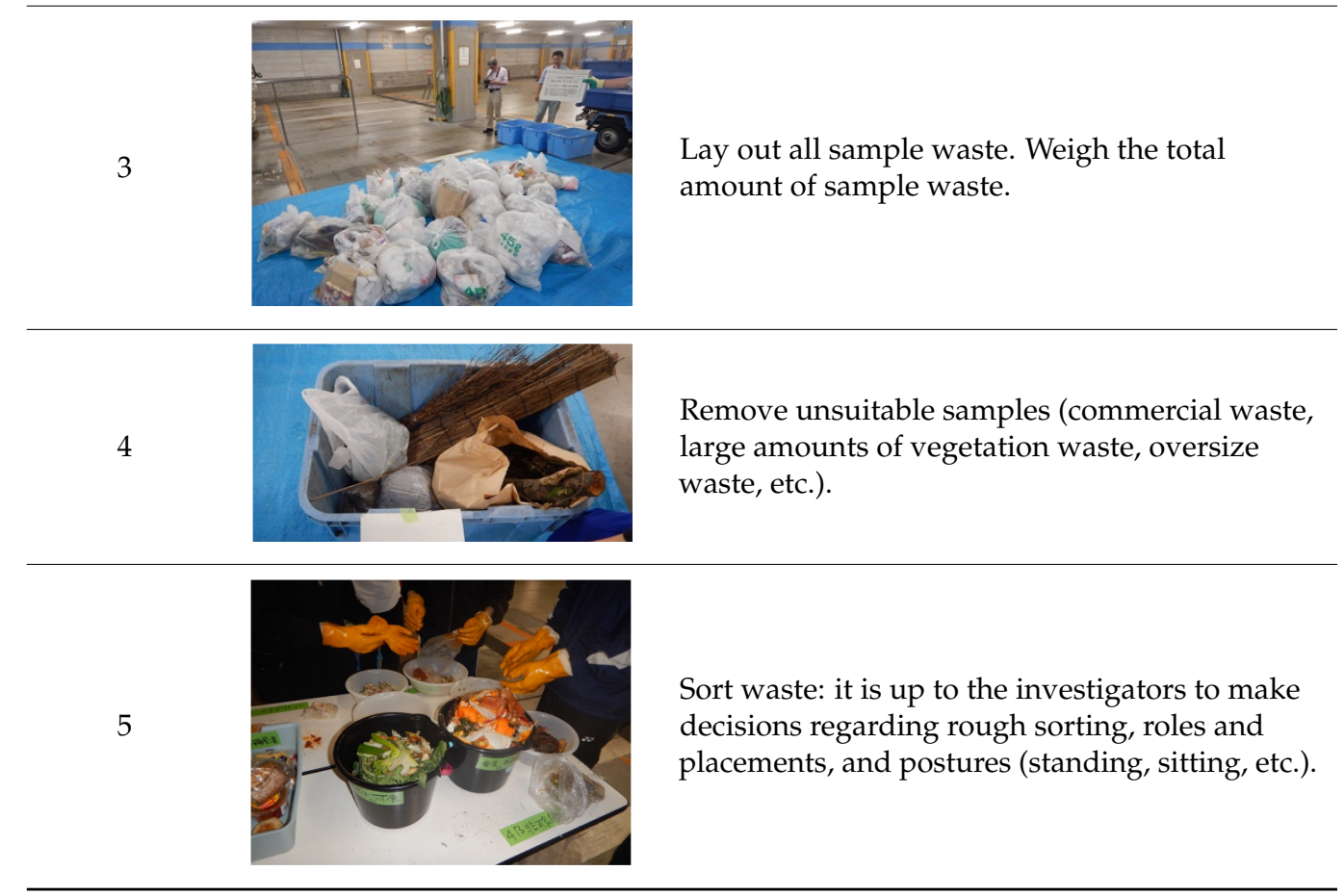


Table A1. Cont.

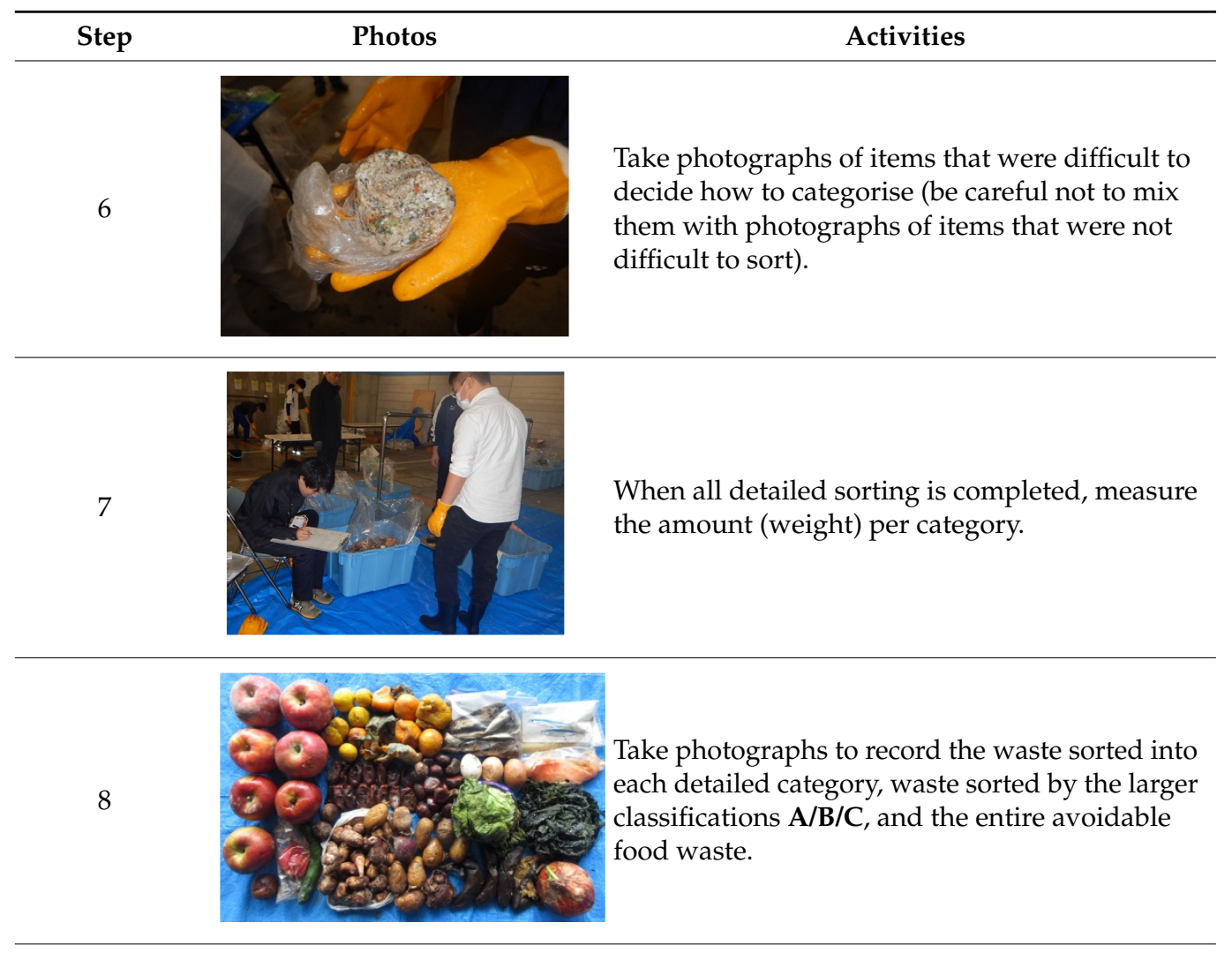

9

10

\section{Appendix B. Further Discussion on the Sorting Analysis Results-Possible Differences between Urban and Rural Areas}

From the results of the sorting analyses, we tried to identify the differences in trends between urban and rural areas. However, regardless of regional characteristics, no major tendencies were identified in terms of the composition of food waste, assumedly because the lifestyles of Japanese people are basically similar throughout the country; whether in urban or rural areas, people basically go to the supermarket to buy food and prepare dishes at home. However, Setagaya and District $X$ in the central part of Tokyo tended to have less of category A than in the rural areas (Seika Town and Nagai City). It is possible that residents in rural areas tend to prepare meals with raw ingredients while urban dwellers tend to rely more on processed food items, and the waste composition 
reflected this tendency. In the future, more survey results should be accumulated to verify this trend.

We can notice that the results of food waste in combustible waste in the rural areas of Seika Town in December 2019 and Nagai City were similar, with a significant presence of wasted home-grown vegetables (A2wf). Moreover, in the separate collection of food waste in Nagai City, home-grown vegetables accounted for $16.3 \%$ of total separated collection of food waste, and $37.8 \%$ of avoidable food waste in this fraction. This separate collection is provided in the urbanised part of Nagai City to promote the composting of food waste even if it is difficult to find a space to do so at each household. Apparently, in rural areas, there is an awareness of the need to actively recycle unused vegetables into compost due to over-harvesting or receiving too much. It can be pointed out that a characteristic of avoidable food waste in rural areas is the presence of home-grown vegetables.

\section{References}

1. FAO. Global Food Losses and Food Waste-Extent, Causes and Prevention; FAO: Rome, Italy, 2011.

2. FAO. Food Wastage Footprint. Impacts on Natural Resources; FAO: Rome, Italy, 2013.

3. UNEP. Food Waste Index Report 2021; UNEP: Nairobi, Kenya, 2021.

4. FUSIONS. FUSIONS Definitional Framework for Food Waste Full Report; SIK-The Swedish Institute for Food and Biotechnology: Göteborg, Sweden, 2014.

5. Lebersorger, S.; Schneider, F. Discussion on the methodology for determining food waste in household waste composition studies. Waste Manag. 2011, 31, 1924-1933. [CrossRef] [PubMed]

6. Elimelech, E.; Ayalon, O.; Ert, E. What gets measured gets managed: A new method of measuring household food waste. Waste Manag. 2018, 76, 68-81. [CrossRef] [PubMed]

7. Quested, T.; Easteal, S.; Ingle, R. Methods Used for Household Food and Drink Waste in the UK 2012, Annex Report (v2); WRAP: Banbury, UK, 2013.

8. Nicholes, M.J.; Quested, T.E.; Reynolds, C.; Gillick, S.; Parry, A.D. Surely you don't eat parsnip skins? Categorising the edibility of food waste. Resour. Conserv. Recy. 2019, 147, 179-188. [CrossRef]

9. Food Loss \& Waste Protocol. Food Loss and Waste Accounting and Reporting Standard Version 1.0. 2016, p. 68. Available online: http:/ / flwprotocol.org/wp-content/uploads/2017/05/FLW_Standard_final_2016.pdf (accessed on 23 March 2021).

10. Japanese Ministry of Environment Procedure for Sorting Analysis of Waste Disposed in Garbage Bags for Understanding the Generation of Household Food Loss (May 2019 Ed.). 2019. Available online: http://www.env.go.jp/recycle/tejyunnsho.pdf (accessed on 23 March 2021). (In Japanese)

11. Japanese Ministry of Agriculture, Forestry and Fisheries. Outline of Food Loss Statistics Survey (Survey of Households and Food Service Industries). Available online: http:/ / www.maff.go.jp/j/tokei/kouhyou/syokuhin_loss/gaiyou/index.html (accessed on 23 March 2021). (In Japanese)

12. Yamada, T.; Asari, M.; Miura, T.; Niijima, T.; Yano, J.; Sakai, S. Municipal solid waste composition and food loss reduction in Kyoto City. J. Mater. Cycles Waste Manag. 2017, 19, 1351-1360. [CrossRef]

13. Asari, M.; Yano, J.; Sakai, S.; Hasegawa, K.; Koizumi, H.; Takatsuki, H.; Nakamura, K. 40-year Waste Compositional Analysis Reveals Trends in Generation of Kyoto Food Waste. Mater. Cycles Waste Manag. Res. 2020, 31, 273-284. (In Japanese)

14. Quested, T.; Ingle, R.; Parry, A. Household Food and Drink Waste in the United Kingdom 2012; WRAP: Banbury, UK, $2013 ;$ p. 92.

15. WRAP (Waste and Resource Action Programme). The Food We Waste; WRAP: Banbury, UK, 2008; p. 211.

16. Japanese Ministry of Environment. Report of the Supporting Scheme for Municipal food Waste Survey (FY2020). Available online: https: / /www.env.go.jp/recycle/foodloss/pdf/r2shikusyokujittai.pdf (accessed on 23 March 2021). (In Japanese)

17. Beigl, P.; Happenhofer, A.; Salhofer, S. Technical Instructions for Conducting Residual Waste Sorting Analysis; Institute of Waste Management, BOKU University Vienna (ABF-BOKU): Vienna, Austria, 2017. (In German)

18. Schneider, F. IWWG Task Groups activities during the Sardinia 2011 Symposium-Prevention of Food Waste Task Group, in Bonomi, E. Ed. IWWG News \& Views. Waste Manag. 2012, 32, 352-356. 